Authors' pre-print version

To be published as: Tutenel, P., Heylighen A., Interweaving vulnerability and everyday design: Encounters around an aquarium in a paediatric oncology ward, Design Studies

Please refer to the final published version. 


\section{Interweaving vulnerability and everyday design: Encounters around an aquarium in a paediatric oncology ward}

Piet Tutenel, Ann Heylighen

KU Leuven, Dept. of Architecture, Research[x]Design, Kasteelpark Arenberg 1/2431, BE-3001 Leuven, Belgium

Abstract

Contemporary understandings of vulnerability highlight its critical, relational and enabling aspects. Through leveraging these understandings, this article contributes to conceptualizing the notion of everyday design by interweaving it with that of vulnerability. A case study brings vulnerability into view by zooming out from and in on everyday practices around an aquarium in a paediatric oncology ward. Subsequently, we unravel the notion of vulnerability as used in design research and in anthropology and philosophy: while vulnerability grounds everyday design philosophically and ethically as a form of care, everyday design challenges the tendency to situate vulnerability in (relations between) human beings. Our article thus exemplifies design anthropology understood as bringing in dialogue theory and methods from both anthropology and design.

Keywords: affordance, built environment, case study, design research, vulnerability

Highlights

- We leverage understandings of vulnerability from anthropology and philosophy

- We show how these align with research about the indeterminacy of design

- We propose to ground everyday design philosophically and ethically as a form of care

- We show how design research challenges tendencies to situate vulnerability in humans

- We exemplify design anthropology as bringing anthropology and design into dialogue 
This is our starting point: a mundane, everyday encounter around an aquarium in a paediatric oncology ward of a large scale university hospital in Belgium, namely that of a boy and his matchbox car racing the aquarium fish in the parents' corner (Fig. 1).

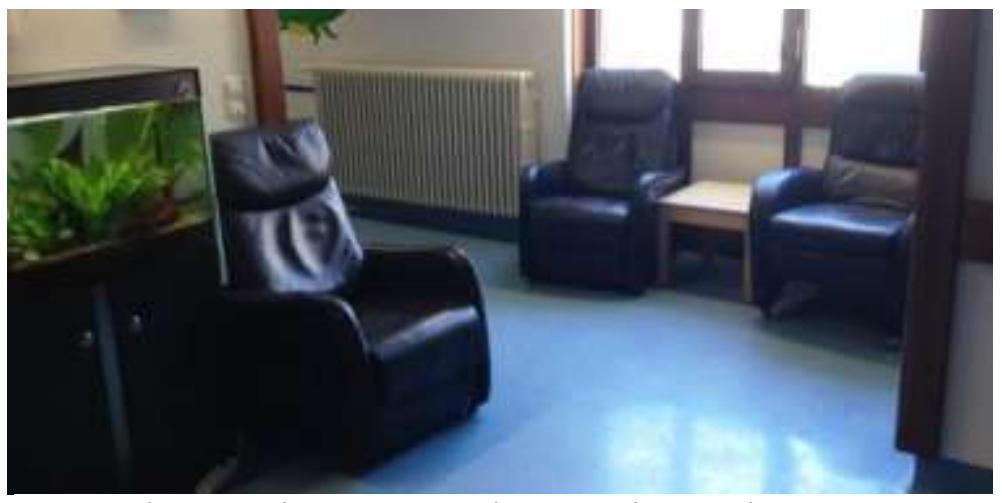

Figure 1: The parents' corner in a paediatric oncology ward

(C) (Laure Verschoren, 2014)

We write about it here because it might have something to tell readers of this special issue on Design Anthropology. Inspired by anthropological and philosophical research that situates vulnerability in and as everyday and often unnoticed encounters (e.g., Das, 2015; Laugier, 2016), we challenge the reductively negative understanding of vulnerability as it is commonly used in design research ${ }^{1}$ and aim to contribute to conceptualizing 'everyday design' (Wakkary \& Maestri, 2008) by interweaving this notion with a more enabling understanding of vulnerability.

We elaborate this in two parts: the first part explores the hospital aquarium as a case study. To bring into view vulnerability in the paediatric ward, we use the metaphor of zooming out from and in on socio-material practices (cf. Nicolini, 2009; van Dijk and Rietveld, 2017). Think of a city park: a zoomedout perspective would allow noticing patterns, while zooming in would reveal human and other-thanhuman agents caught up in many different ongoing activities. The zoomed-out perspective in our case study shows the aquarium as part of stable and persistent orders and practices, presumably to reassure and comfort children (and their care workers). Zooming in draws a different picture of vulnerability in the ward by looking from within an unfolding situation. Here the aquarium and other aspects of the material arrangement it is situated in are (also) vulnerable.

The second part grounds the article in a theoretical discussion on the notion of vulnerability. We start by sketching the different uses of vulnerability in design research and confront them with its use in (mostly) feminist ethical, philosophical and anthropological studies. The latter, we argue, resonates with recent scholarship in design anthropology, geographies of architecture, architectural research and $\mathrm{HCl}$ that understands everyday practices like maintenance, re-valuing and support as ongoing design

\footnotetext{
${ }^{1}$ For an exception, which we will come back to, see the work of Cipolla (2018).
} 
(e.g., Jackson, 2014; Jacobs \& Merriman, 2011; Pink et al., 2019), highlighting design's indeterminacy and contingency.

Gunn et al. (2013) understand design anthropology as bringing in dialogue theory and methods from both anthropology and design. Our article exemplifies this in four ways, through: (1) resulting from collaboration between an anthropologist and a design researcher; (2) interweaving notions from both disciplines: an enabling understanding of vulnerability with that of everyday design; (3) exploring the potential of this understanding of vulnerability to empirically study and theorize situated everyday design practices; (4) highlighting the relevance of extending this understanding in design research and the contribution of design research to critical inquiries into the conditions of human life (anthropology/philosophy).

\section{The case around the hospital aquarium}

The case study is part of a broader research project which explores how the experiences of 5-to-18years old children and youth affected by cancer - and their siblings - can inform the design of cancer care environments. For this case study, fieldwork and analysis were a collaborative endeavour of both authors, an anthropologist and a design researcher. ${ }^{2}$ The fieldwork was conducted by the first author (henceforth: the researcher) between October 2018 and January 2019. During the fieldwork the ward was moved to a new building.

According to Mol (2008, p. 32),

'a case is something to explore, to learn from. It is specific and surprising. Attending to it carefully may make you reconsider what you thought was clear and distinct. It may interfere with your very language. And while a case cannot be generalized, neither is it local. Instead, its specificities are made to travel. When you move a case around, new things start to happen.'

The thing we focus on in this case study is, as mentioned, the ward's aquarium. Inspired by Schatzki's (2002) practice theory and Gibson's (1979) theory of affordance, we develop a socio-material approach to explore everyday (design) practices of and with children by focusing on mundane artefacts (Tutenel et al., 2019b) like an aquarium. We adopt a 'thing-perspective' (Giaccardi et al., 2016) with the aim to better understand design-use relations and in particular to understand children, and other (f)actors, as everyday designers; as active constituents of the world and as situated in relation to everyday

\footnotetext{
2 The team of the broader 'Room for Vulnerability' project is composed of three members with different backgrounds: in architectural engineering, educational sciences, and social anthropology. The research project is embedded in the Research[x]Design group at KU Leuven (Belgium) housing researchers and practitioners from various nationalities, with different abilities and educational backgrounds including: architectural engineering, (interior) architecture, industrial design engineering, social anthropology and geography, computer sciences and religious studies.
} 
environments contributing to its making (Hackett et al., 2015). Studying everyday (design) practices thus becomes a means to study spatiality (Tutenel et al., 2019b). By focusing on the doings of and around the ward's aquarium, we show how design goes on through children's participation in practices and activities on the one hand. On the other hand, this thing-perspective blurs distinctions between humans and other-than-humans, producers and produced (Giaccardi et al., 2016).

A remark made in a meeting of the research project's advisory board led us to focus on the ward's aquarium. The researcher showed a video fragment of the move in which the aquarium appeared. Afterwards the head of technical services of the hospital made a remark about how the staff had had to fight for this aquarium's place in the new building because the design of the air flow system could cause infection problems. We were struck by how the children, staff and other adults find this aquarium so important and by its connection with so many people and things in the hospital. If an artefact like an aquarium is able to gather so many people around it, it is surely worthwhile being attentive to (cf. Law, 2019).

We use different types of data to build up our case study. We start from observational field notes collected by the researcher during the study. He visited the hospital two days per week - mostly during regular working hours. While being in the hospital he watched, listened, talked to people, and wrote.

Next to the notes we use action camera-video images shot by three participants (three boys, two 15and one 5-years old at the time of the fieldwork). They were initially asked to join the study by the hospital's psychologist whom they know well. The researcher and the boys (and sometimes a (grand)parent) met 22 times at the ward, the day-care ward or the outpatient centre. All three participants were in an advanced treatment stage and thus used to visiting the hospital. The meetings lasted between 20 min and 1,5 h depending on the children's mood, energy level or therapeutic interventions necessary. During the meetings the participants and researcher jointly discussed the research, filmed and reflected on the images, 'constructing collaborative presentations' (Milstein, 2015) of everyday practices in the paediatric hospital (Tutenel et al., 2019ab). Rather than asking specific questions, they explored (what goes on in) the ward through working with video (Pink, 2013; Tutenel et al., 2019a) (Fig. 2). 


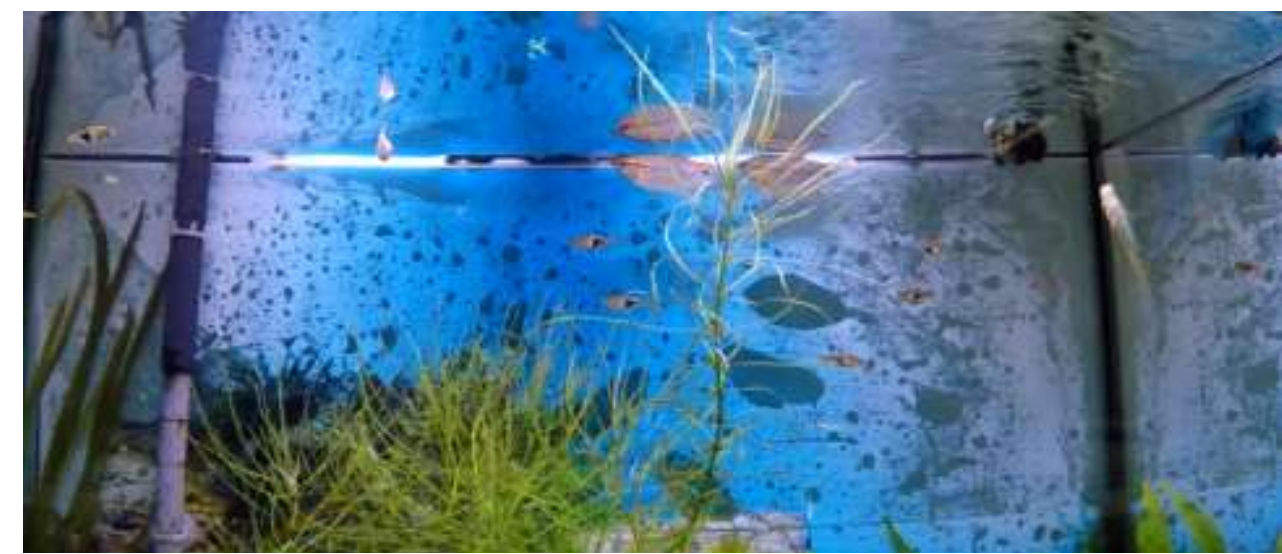

Figure 2: Still frame taken from a video made during a research meeting by one of the participants and his grandfather exploring the ward's aquarium with an action camera. (C) (Participant of the Room for Vulnerability project, 2018)

Next to analysing the images and field notes, we searched for aquaria in hospital photographs throughout the history of children's hospitals.

\subsection{Analysis: Zooming in on and out from practices and material arrangements}

a. The zoomed-out perspective: Depicting children as vulnerable

Below we discuss the aquarium as part of stable orders and practices through how it appears in historical hospital photography.

Researchers trying to understand the complex cultural positioning and social meaning of childhood embodied in healthcare settings have already used historical photographs taken of and by hospitalised children (Adams et al., 2009). According to Adams et al. (2009), two types of photographs stand out: the first, a therapeutic type, depicts the hospital as a place where heroic physicians use technology to heal children, exposing young patients as frail and helpless; the second type, images of playfulness, promotes the institution as a place of socializing and fun. Historical images we found in which the aquarium appears fit in this last group. ${ }^{3}$ Through the aquarium these pictures frame the hospital as an ordinary and welcoming place for children, with little indication of the medical technology that characterises the therapeutic pictures.

\footnotetext{
${ }^{3}$ Home and public aquaria date back to the $19^{\text {th }}$ century when people started to better understand the relationship between oxygen, animals and plants (Olalquiaga, 1998). Since their invention in 1832 as an observation tool, aquaria evolved into tuned spaces and dwelling sites for other-than-human life (Schmitt, 2017). People across the world keep home aquaria as calming micro-worlds, helpful in reducing levels of stress and anxiety (Langfield \& James, 2009). Possibly, this explains their frequent inclusion in healthcare settings (Cracknell et al., 2016). When being in the hospital, patients and their families experience fear, anxiety and stress (e.g., Rokach, 2016). The common belief that watching fish is calming and relaxing - a positive distraction - is also supported by some studies (for a recent review, see Clements et al., 2019) which show beneficial physiological or psychological responses to watching live fish in small tanks, video footage of aquarium fish, or more recently digital interactive aquariums. A recent review on how interacting with fish in aquaria affects human health and well-being (Clements et al. 2019) suggests that little is known about the specific benefits of human-fish interaction.
} 


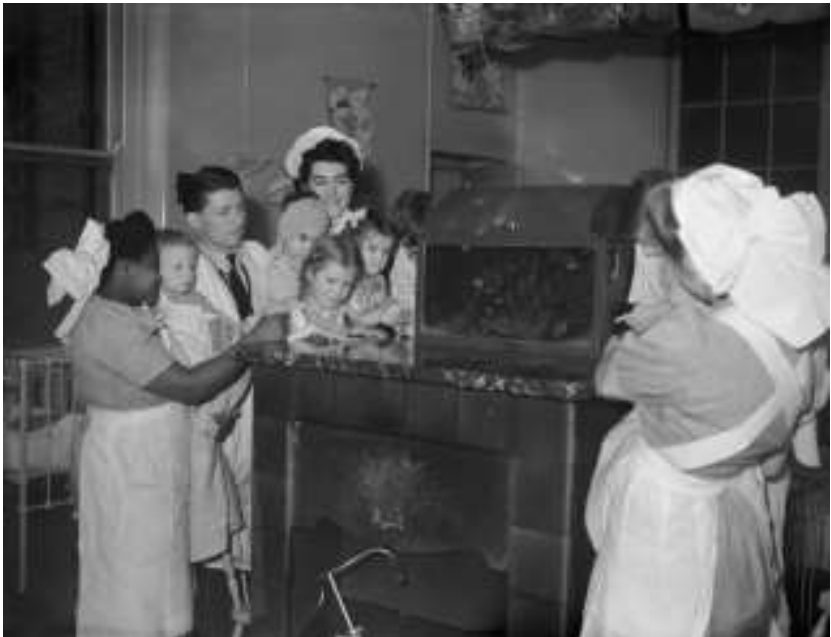

Figure 3: Prince of Wales General Hospital (Tottenham, 1948)

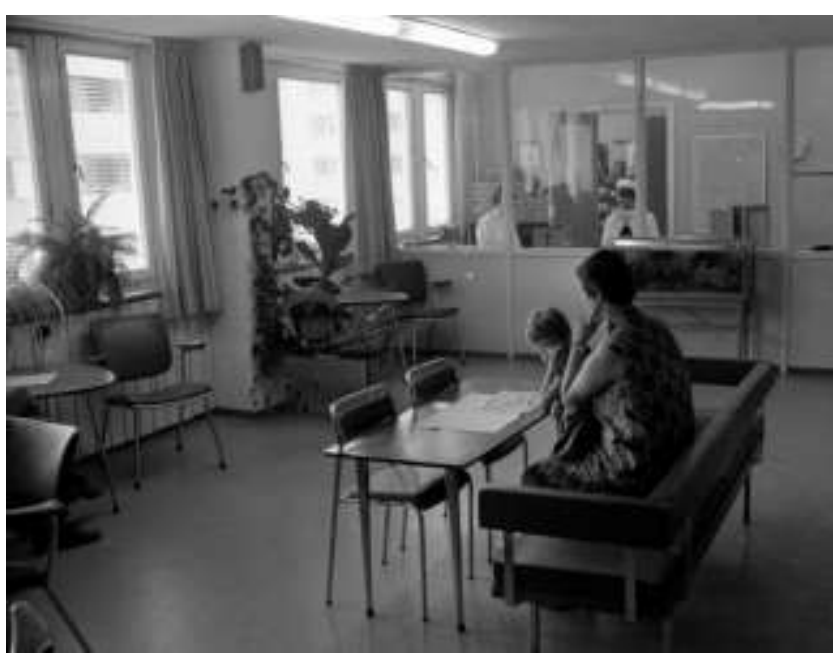

Figure 5: Paediatric hospital (Poland, 1968)

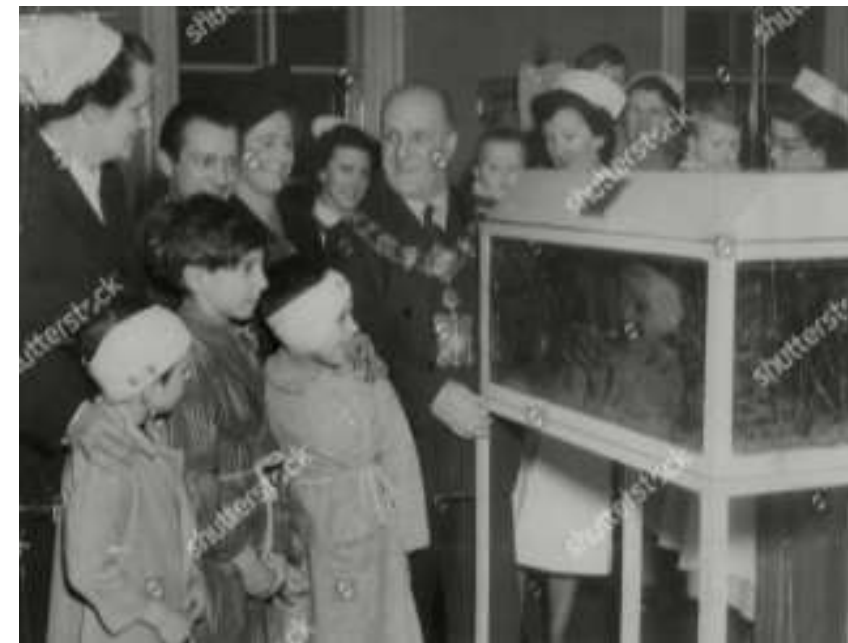

Figure 4: Hackney Hospital for Children (London,1951)

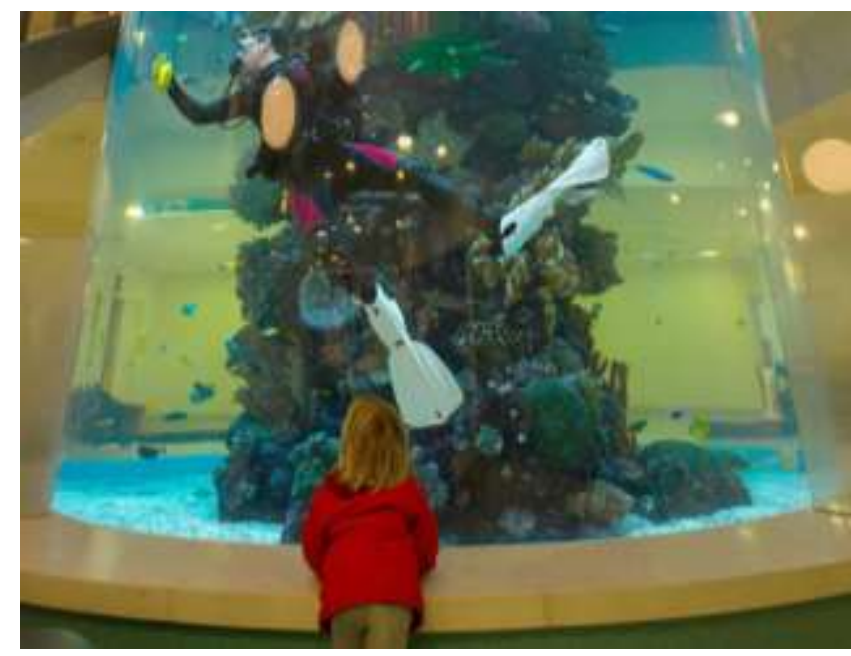

Figure 6: Royal Children's Hospital (Melbourne,2012)

The oldest picture we found dates back to April 1948 (Fig. 3). It is taken in the Prince of Wales General Hospital in Tottenham (UK). The picture shows children and staff gathered around the newly installed aquarium. In another example, a picture from 1951, the mayor of Bethnal Green aquatic society is presenting an aquarium on behalf of the aquatic society to the children's ward at the Hackney Hospital for Children (UK) (Fig. 4). As in Fig. 3, the children and staff appear to be happy looking at their new aquarium. Figure 5 is taken in a hospital waiting space in Poland (1968) showing a woman and a child while waiting with the aquarium in the back. Figure 6 shows a child gazing at the impressive two-story aquarium in the Royal Children's Hospital in Melbourne. A partnership with SEA LIFE, Melbourne Aquarium led to its inclusion in the design of the paediatric hospital.

This brief exploration of historical hospital photographs suggests that over the past century the aquarium has become a common artefact in practices of care in different parts of the world. There is a shared understanding how (or at least: that) this artefact takes part in care practices. The photographs seem to emphasize the aquarium's role to offer children distraction while being in the hospital. For 
example, the picture taken in the Royal Children's Hospital in Melbourne (Fig. 6) may as well be taken in a shopping mall. As a contrast to the medical machinery related to illness and treatment, installing an aquarium can be understood as part of the material arrangement that seeks to make the hospital a homelike environment. Without the nurse caps and aprons or the children's head bandages, it would, indeed, be very difficult to recognize the setting of the pictures as healthcare environments (Fig. 3,4,6). Before the aquarium's introduction photographers used other artefacts (e.g., toys, houseplants, bicycles, tea sets) to depict the hospital as a welcoming place for children (e.g., Adams et al., 2009).

The zoomed-out perspective aligns with research that shows how designers and care workers alike have been using artefacts like an aquarium to humanise and normalise children's hospital environments throughout its history (cf. Adams, 2017; Bates, 2018). From this perspective the children appear to be vulnerable (e.g., wearing head bandages, waiting for a doctor's appointment, being surrounded by nursing staff); in need of healthcare environments that feel safe, homelike and supportive to cope with the stress of illness and treatment. It confirms such discourses surrounding childhood are embodied in the (ongoing) design of healthcare settings (cf. Adams, 2017; Prior, 1988).

b. The zoomed-in perspective: From within an unfolding situation the aquarium is (also) vulnerable While the first, zoomed-out, perspective allows us to observe the aquarium as part of stable and persistent orders and practices within a healthcare environment, the second one looks from within an unfolding situation, namely of a boy racing the aquarium fish in the parents' corners of the old paediatric oncology ward (Fig. 1; 7). During the first days of fieldwork in the old ward, a staff member explained that the parents' corner had been designed by the staff. Like in some of the examples above, the aquarium was a gift of gratitude from a parent for the good care for their child, as were the orange garden chairs. 


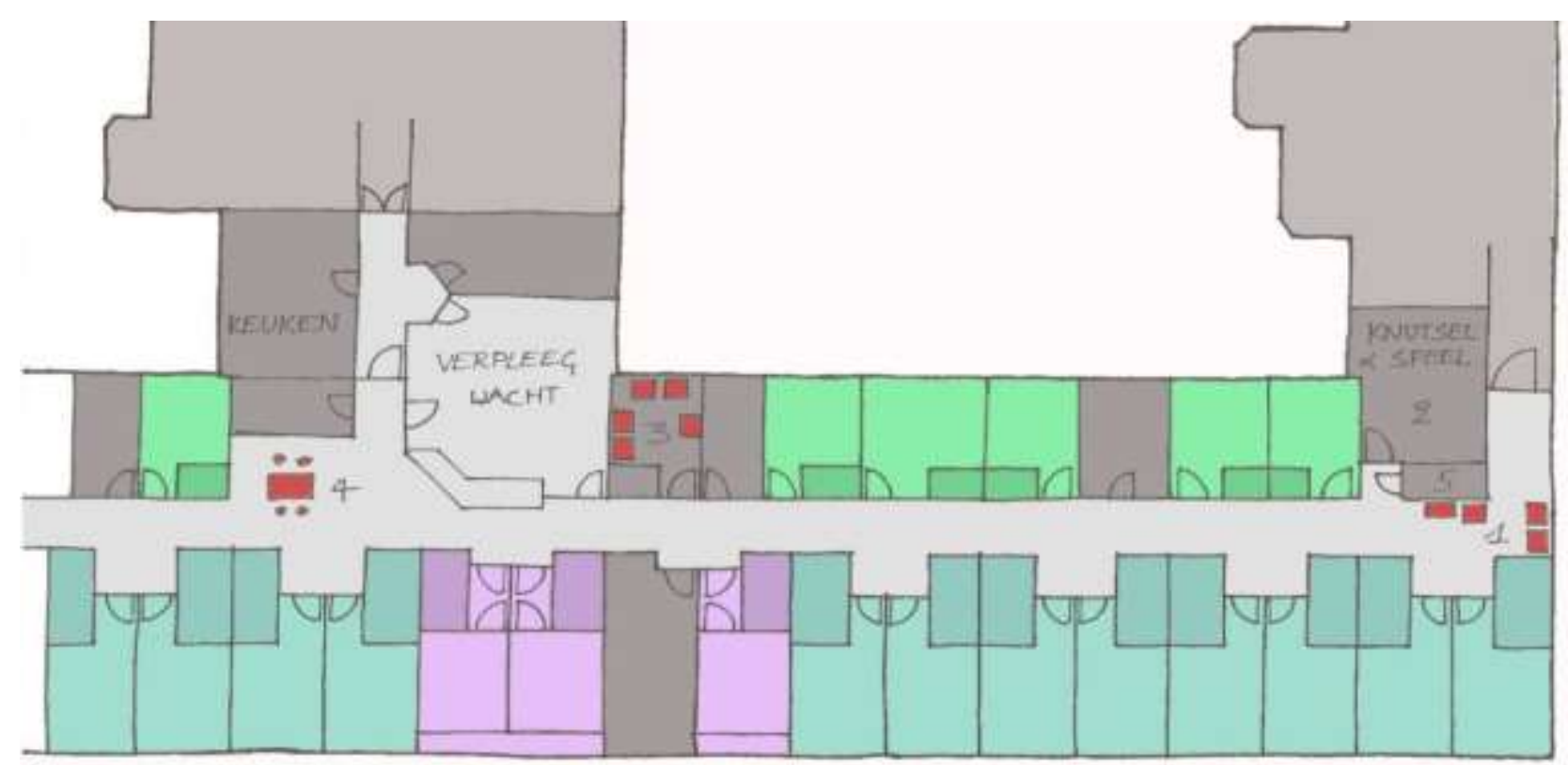

Figure 7: Diagrammatic floor plan of the old ward, (C) (Laure Verschoren, 2014); nr. 1: Parents' corner, nr. 2: playroom, nr. 3: parents room, nr. 4 meeting space, nr. 5 kitchenette

In the ward, the aquarium was located in the parents' corner (Fig. 1). This corner was situated at the far end of the ward. The aquarium was located against the wall in between one of the armchairs and one of the garden chairs.

The situation we describe is by no means exceptional - ethnography as the discovery of the ordinary (Van der Geest, 2015). On the contrary, we choose this situation because it is so everyday and unspectacular. We focus on it not to reveal something that is hidden. Rather our presentation draws attention to what is always already there to be seen. Concentrating on everyday practices and seeing what happens there might make something become thought-provoking, not only about this particular aquarium, about this one boy or about this hospital.

Researcher's considerations: Noticing a moment of care around the ward's aquarium

It must be around 10 o'clock because the teachers are walking through the ward with their laptops. I am seated in one of two the seats close to the window. A man is sitting in the seat next to me. His cup of coffee on the table and a book on his lap. His eyes are closed, he is resting. Next to the aquarium are two orange garden chairs. In the one next to the aquarium a mother is having breakfast while keeping an eye on the door of her son's room. Another woman is sitting in the other one being on her smartphone while her son is driving a matchbox car on the glass of the aquarium. A nurse comes out of the patient room close to the parents' corner. She pushes the alcohol gel dispenser and cleans her hands. "What are you doing?", the nurse asks. "I'm racing the fish", the boy says. "Oh, who's winning?" the nurse replies. "The white one.", the boy answers. "He's racing, I'm looking at the "dagelijkse kost"-app"; looking for recipes", the boy's mother replies smiling. "Yeah, that's also one of mine 'autistische kantjes"s" the other

\footnotetext{
4 "Dagelijkse kost" is a famous cooking TV show in Belgium.

5 'Autistische kantjes' is Dutch for 'autistic sides of self'.
} 
woman replies. "Dirk [her partner I suppose] and I always have discussions about it; that's the only good thing about being in the hospital", she says, "you don't have to worry about what to eat so much". "That's true", the nurse replies while tapping her finger against the aquarium to encourage the fish to race the matchbox car.

This second perspective allows us to identify different practices by highlighting what the aquarium is involved in and what takes place around it. These are practices and activities such as waiting, being passed by, feeding the fish, cleaning the aquarium, looking for recipes, resting, having breakfast, being on a cell phone, keeping an eye on the door, cleaning one's hands, racing the fish, having a conversation, or doing nothing in particular. This is not to say that the aquarium is always of interest from the perspective of the humans involved in these ongoing practices and activities, nor is it the most determining. Nevertheless, it plays a part in ongoing arrangements and practices, it is there and makes certain things possible - and others impossible. Because of the indeterminacy of practices (Schatzki, 2002), without the aquarium the situation would have evolved differently. Some of these practices compliment the role aquariums are commonly assumed to play in healthcare environments; to contain fish and plants for observation and to provide positive distraction. We also see how it is involved in all kinds of other activities (e.g., affording conversation along, racing).

This zoomed-in perspective allows us to observe that design goes on dynamically and relationally because different 'actors' improvise upon or around the aquarium in the parents' corner. The aquarium is re-designed throughout the day because of its involvement in ongoing arrangements and practices. Analysing the situation with the aquarium as empirical focus, we understand how design inherently goes on situationally (relational, dynamic, in flux). We could say that, in this particular situation (which the aquarium is part of and shapes at the same time), the aquarium connected with the fish and the boy with his matchbox car and it became a racetrack - in this situation the aquarium afforded raceability. Following the race between the matchbox car and the fish is interlaced with conversations about things like meals at home and in the hospital. Possibilities for 'small acts of care' (Brownlie \& Spandler, 2018, p. 267) emerge in and through children's participation in everyday practices in the ward. One could interpret the situation as a well-targeted tactful action of the nurse to develop a relationship with the boy and the parents who are sitting there, but this may be a too narrow view. We suggest that the situation also, and primarily, brings into view that being in the hospital is also about simple forms of taking care of things in the world and of one another (Puig de la Bellacasa, 2012).

From within this unfolding situation (an everyday encounter around the hospital aquarium) a different, enabling picture of vulnerability can be drawn. Our situational approach suggests that spaces/artefacts offered the boy possibilities for action that cannot be anticipated; the parents' corner became a 
playground, the aquarium became a racetrack, etc. From within an unfolding situation ongoing forms of designing are revealed (Sumartojo et al., 2020). The situation we described shows that design (also) goes on in the continuous flow of events that befall humans and other-than-humans (Schatzki, 2002). Through its involvement in everyday practices, the aquarium co-creates situations and makes caring (for) possible. What is vulnerable from this perspective is the contingency and indeterminacy of the ordinary everyday and, because of this vulnerability we cannot control what the world means (cf. Hodgson \& Ramaekers, 2019, p. 80 on vulnerability and upbringing).

\subsection{Closing the case study: Vulnerability as taking place in between entities}

In this case study we focused on a 'thing' (Giaccardi et al., 2016), a hospital aquarium, to explore vulnerability in the hospital. We did this by zooming in on and out from practices the aquarium is involved in. The zoomed-out perspective reveals how it is deeply embedded in well-established care practices across the world aimed at reducing stress in healthcare environments. The historical pictures depict children as vulnerable, in need of positive distraction. The second perspective pointed at concrete doings of and around the aquarium and its ability to gather around it people and other artefacts (like matchbox cars and cell phones). Zooming in foregrounds how its planned-for activities are re-programmed through and in everyday practices (Raff \& Melles, 2015); that is: in the encounter between the aquarium, the fish, the boy and the matchbox car. The situation shows how the aquarium is re-designed in and through everyday encounters, revealing its vulnerability. In these encounters design-use relations showed up as situated, unfixed and undetermined - before that boy started racing the fish it would have been impossible to predict the aquarium would invite him to do so.

To deny the realities that correspond to the general discourse of vulnerability with regard to hospitalized children affected by cancer would be very short-sighted. Yet, as our case study makes clear, these children are not only vulnerable or passive, subjected to the reality of illness and of the hospital, but also active constituents of the world (cf. Hackett et al., 2015). The boy's world appeared to be less determined, even in a highly structured environment like a child oncology ward.

To further clarify our way of thinking, we present in the next part of this article an analysis of the notion of vulnerability as it is used in design research and in anthropology and philosophy. In line with the zoomed-out perspective, vulnerability in design research is commonly understood as negative and something to avoid and to be protected from. Contemporary anthropological and philosophical understandings of vulnerability, however, conceptualize vulnerability not so much as a quality embedded in entities, but as something that takes place in between different entities. This relational understanding of vulnerability showed up in the zoomed-in perspective and aligns, we argue, with 
design (anthropological) approaches that emphasize design's unfinishedness and openness as integral to design.

\section{Exploring the notion of vulnerability in design research and in anthropology and philosophy}

2.1 Vulnerability in design research: A problem to be solved

Together with the further recognition and understanding of design's influence on social life and change (e.g., inclusivity, sustainability, (social and environmental) justice, care, resilience and community building), the past decade has seen a proliferation of design research that engages with vulnerability. The concept, however, is used and understood in various ways. It is used, firstly, to characterise an individual or a certain group of people. People are considered vulnerable due to their social-economic status, or their psychological or physical capacities, e.g., children, women, older people, people with an impairment, people confronted with disease, refugees, and homeless people (e.g., Almohamed \& Vyas, 2016; Culén \& van der Velden, 2013; Gatehouse et al., 2018; Macdonald et al., 2010; Schepers et al., 2018; Slegers et al., 2013). This use of vulnerability is found in participatory, co-, and inclusive design research. For example, Vines et al. (2013) look at the experiences and needs of people considered vulnerable and discuss the methodological, emotional, and moral challenges for design researchers working with them. Here vulnerability can be linked to discourses of 'giving voice', 'othering', 'emancipation', and 'empowerment'.

Besides 'wanting to give voice to' people considered vulnerable, designing away their vulnerabilities or being inspired by them, some studies consider how objects, spaces, and material environments can make certain people vulnerable by hampering them to participate in practices (e.g., Boys, 2016; Imrie \& Thomas, 2008). In her study on vulnerability and housing, Bartram (2016), for example, emphasizes the importance of investigating relationships between social and material vulnerabilities (e.g., Burrell, 2014). As a case in point, Bartram (2016) refers to Miller's (1988) study of a state-subsidised housing estate in London. Miller observes that some residents radically transformed their kitchens, where others made no changes. Miller attributes these differences to divergent attitudes among residents about their status as council housing tenants: those who felt the most alienated did not make changes, while the others used aesthetics to draw away attention from original fixtures and towards individualised décor. 
Vulnerability as a concept is used, finally, in relation to aspects of sustainability (Kendall et al., 2008), or in assessing the vulnerability of designed objects by looking at their material properties in relation to different contexts: for example, in relation to natural hazards as in Lagomarsino's (2006) study on seismic vulnerability in monumental buildings, or in relation to possibilities of terrorism in high-rise buildings (Kang \& Lee, 2014).

This brief overview indicates that vulnerability in different design disciplines is considered as situated in the relation between objects, humans, and environments and as something to be avoided or reduced. These uses of vulnerability in design as 'a problem to be solved' tie in with its conception as generally assumed in everyday discussions as well as in more theoretical approaches to questions of ethical relevance and to wicked problems (Bache et al., 2015). The concept's different uses in design research share with its common use a reductive and negative understanding (Gilson, 2016, p. 74):

'On such an understanding, vulnerability is equated with susceptibility to harm; it is considered a condition of weakness, dependency, passivity, incapacitation, incapability, and powerlessness. This view of vulnerability is negative in two senses: first, it is conceived as a condition in which one is liable to be harmed; second, it is conceived as a character trait, a property, or a state that has negative value-is bad-and thus is to be avoided.'

As notable exception we refer to Cipolla (2018) who, in contrast to its general use in design, understands vulnerability as an asset when designing for interpersonal interactions. For her, the main benefit of designing for vulnerability is that it enables the possible emergence of relations and dialogue between humans.

2.2 Vulnerability in anthropology and philosophy: An enabling understanding Also outside design research vulnerability has come to play a prominent role in academic, governmental, and everyday accounts of the human condition (Brown et al., 2017). According to Brown et al. (2017, p. 497), today a 'vulnerability zeitgeist' informs a range of approaches to and interventions in societal challenges. While the importance of vulnerability seems to be generally acknowledged, little consensus exists on what it is. Literature reviews characterize it as ambiguous (Gilson, 2011) and contested (Virokannas et al., 2018). It is a concept with 'many faces' (Brown et al., 2017) which should be 'handle[d] with care' (Brown, 2011) because of its ability to 'undo the world as it is' (Ferrarese, 2016). 
Inspired by Levinas, developments in (mostly) feminist ethics amplify the critical and enabling aspects of vulnerability: rather than as an individual shortcoming and in contrast to the dominant Western image of the autonomous individual person, vulnerability is understood as the ability that befalls people to be touched (passivity) and to touch (potentiality) (Butler et al., 2016; Gilson, 2018; Shildrick, 2002).

'Being vulnerable makes it possible for us to suffer, to fall prey to violence and be harmed, but also to fall in love, to learn, to take pleasure and find comfort in the presence of others, and to experience the simultaneity of these feelings' (Gilson, 2011, p. 310).

For Gilson (2018), vulnerability is defined by four features: first, it is a shared fundamental condition. Second, it is a condition of potential, whereby being vulnerable means being open to an alterity that can be determined only in concrete circumstances. Third, vulnerability is differently experienced by those who are differently situated, hence it is, fourth, ambivalent and ambiguous in both how it is experienced and how it is valued. Accordingly, Gilson (2018, p. 231) argues that this characterisation of vulnerability 'is necessarily connected to relationality'.

Such a 'new' theorizing of (cf. Ferrarese, 2016) the notion of vulnerability is critiqued by, amongst others, philosophers (Donatelli, 2016; Laugier, 2016) and anthropologists (Das, 2015; Han, 2013, 2018). While sharing the attunement to interdependency as inherent to life, these scholars show how the impulse of and to a general theory of vulnerability (as master concept), as described above, has a dark side. Providing a conceptual scheme for vulnerability risks creating an account of it that is external to a world in which such circumstances are endured, but also one that would either replicate or be easily absorbed into categories like 'the vulnerable' (Han, 2018). What is vulnerable in these scholars' way of thinking, however, is not only our lives but also our world and our links with others - the vulnerability of life forms -, which have to be repaired and supported continuously.

Inspired by Wittgenstein's ideas as elaborated by Cavell and Das, these scholars defend a vulnerability which consists of attending to the ordinary that makes our lives possible (Das, 2015; Donatelli, 2016). Following Laugier (2016, p. 212), 'the human is vulnerable. So vulnerability defines ordinariness'. Such an understanding of vulnerability points at the importance of staying close to and carefully untangling everyday situations and looking what they have to say. The difficulty of attending to and presenting the details of the ordinary is reflected in the diversity of terms used in anthropology and philosophy to describe everyday situations: the unseen (Das, 2007), small events (Das, 2015), small nothings (Ferrarese, 2016), minor gestures (Manning, 2016), or the unspectacular (Haisman Page, 2016). What 
these different terms share is that instead of defining what vulnerability is in general terms, they invite to look and to see what is to be found in each situated case. By insisting on details - researching vulnerability happens through the localised and the particular - these terms highlight that vulnerability is done. Vulnerability is linked to simple forms of taking care of things in the world and of one another. It is located not only in the human body but also in the flow of ordinary situations, doings, and sayings, with many (f)actors involved. Above all, these terms reflect the role of theory in descriptions of the vulnerability of ordinary everyday life and help to question whether careful (ethnographic) description should be deployed in service of a theory or, rather, seen to be coextensive with theory itself to arrive at a range of humbler concepts (Han, 2018) - to compliment and reframe overarching perspectives.

\subsection{Making vulnerability explicit in design research}

In design research the latter understanding of vulnerability (cf. supra) has not found its entrance - at least not explicitly. We do, however, find studies in design anthropology, geography of architecture, and across different design fields that focus on the ordinary, the everyday, and understand actions such as repair, support, revaluing, and maintenance as integral aspects of design (Jackson, 2014; Jacobs \& Merriman, 2011; Graziano \& Trogal, 2017). Rather than as finished artefacts (cf. Garud et al. (2008) on the incompleteness of design), they conceptualize designed things, as always 'leaky' (Ingold, 2008) and thus 'open' to other things and processes (Pink et al., 2019).

In design anthropology such an ontological view enables an understanding of design, not as introduced externally or objectively, but as processes constantly, somewhere 'in between' things (Akama, 2015). Broadening the range of practitioners to different kinds of (f)actors leads designers and researchers to rethink and actively engage in co-design. Design anthropology focusses on how human and other-thanhuman agents are mutually constituted in and through (everyday) design practices (e.g., Lindström \& Ståhl, 2019). Studies exploring such everyday design practices concern, e.g., family homes, hospitals, or workspaces, (e.g., Duque \& Popplow, 2019; Pink et al., 2017; 2019). These studies present practices such as cleaning and catering as forms of designing (Sumartojo et al., 2020) and point at the significance of often overlooked artefacts in shaping relations through their participation in care networks (e.g., Araujo et., 2020).

In geographies of architecture, design is understood as ongoing in/through use and the range of practitioners is broadened way beyond professional designers and users; including manufacturers, repair workers, vandals, but also pets and moulds (Jacobs \& Merriman, 2011). Jacobs and Merriman (2011, p. 211) with their concept of 'practicing architectures' have advocated for a need to 'animate 
architecture', which emphasizes a building not as a stable object or container, but as its various performances of 'holding together and not holding together'. For these authors, a focus on the vibrant and contingent nature of the building assemblage opens up a space to include other 'doings', like maintenance and repair, within a broader conception of the work of building. They focus not only on professional designers but also on 'everyday (re)designers' of the built environment (Jacobs \& Merriman 2011, p. 216); intervening in the fabric of a building or re-programming its planned for activities and designed intentions in orchestrated or in more happenstance ways. Thus they point at the contingency and indeterminacy of design. 'Thinking about design in such terms enables us to see how living with the world is always to engage in the practice of drawing things together differently' (Jacobs \& Merriman, 2011, p. 216).

In architectural research this understanding of design(ing) comes to the fore in studies focusing on design-use complexities (Stam et al., 2020). These studies draw attention to how buildings change over time through the texture of ordinary life, in their interactions with users in (changing) contexts (Gieryn, 2002) and on what this means for understanding architectural practice (Awan et al., 2011).

In interaction design, the abovementioned idea of 'everyday design' has been developed over the past decade by Wakkary and his colleagues (Wakkary \& Maestri, 2008). Everyday design, as they came to understand it, denotes that design does not stop when an artefact leaves the drawing board but that everyone of us designs in the course of living our lives (Wakkary, 2009). People creatively act upon objects and environments in order to adapt, appropriate and re-design (repair, re-purpose and resource) them through ongoing design in use (Maestri \& Wakkary, 2011). Everyday design describes the ongoing process of resourcefully using and appropriating everyday artefacts (and systems) as a means to construct everyday life on an ongoing basis (Desjardins \& Wakkary, 2013). These actions are not necessarily intended by the designer, yet people transform artefacts based on their understanding of the current and future situations (Desjardins \& Wakkary, 2013). Besides offering important insights into design-use complexities, these studies also offer possible strategies for professional designers to 'design for everyday designers', e.g., designing interactive artefacts that invite appropriation and adaptation (e.g., Kim \& Lee, 2014;. Kuijer et al., 2017). They argue that recognising the practice of everyday design is not about equating it with professional design practices, but about engaging in dialogue (e.g., Boeva \& Foster, 2016; Raff \& Melles, 2015). 


\section{Conclusion: Exemplifying design anthropology by interweaving vulnerability and everyday design}

By way of conclusion we now come back to the aim we set out at the beginning of this article: to contribute to conceptualizing everyday design by interweaving it with the notion of vulnerability.

Vulnerability as we have come to understand it is neither an a priori normative category nor merely indicating a form of injury or susceptibility to harm, but rather 'a general openness to the other' (cf. Gilson, 2013; Petherbridge, 2016). This general openness includes not only human others but also other-than-humans, the world, our forms of life that are vulnerable and in need of constant support (cf. Laugier, 2016).

The zoomed-out perspective shows that the aquarium has become part of our forms of life. The historical examples explored through hospital photography enabled us to observe that the aquarium takes part in practices of care in healthcare environments. Zooming in allowed us to focus on how the aquarium contributes to the constitution of such practices and on what takes shape around it. The situation we described when zooming in may best, and foremost, be understood as an unspectacular almost unnoticeable reminder of the vulnerability of our world: in that mundane encounter between the boy with his matchbox car, the fish, and the aquarium, the latter became a racetrack. In that situation the boy seemingly did not notice or care about the difference the aquarium is intended to make and at the same time small acts of care emerged in the encounter. Recognizing vulnerability, as it is understood in anthropology and philosophy, corresponds to a quite ordinary reality and invites us to carefully attend to and give an account of what we are unable to see, but is right before our eyes, and the ongoing work of care conceived as the maintenance, continuity, and protection of the world and form of life (Laugier, 2015). Understanding the boy's participation in practices as everyday designing brings into view not only that our world is vulnerable (in need of protection and support), but also that children actively care for the world by engaging in it in their own way (and not only are being cared for by humans and other-than-humans) (e.g., Rautio, 2013; Ramioul et al., 2020). Recognizing vulnerability as such may be about (design) researchers and children experiencing that the world finds itself in an 'uncertain' (Akama et al., 2015) and 'undecided' state (Noens, 2017) and that, through mundane tinkering with the world, things receive (new) meaning (Mol et al., 2015).

Our contribution to design anthropology lies in showing, through a specific case study and a theoretical discussion on the notion of vulnerability, not only what a dialogue between anthropology and design research can look like, but also, and more importantly, what it might do. To finish this article we therefore turn to what this dialogue brought into motion. 
3.1 The contribution of vulnerability to design research

Broadening our understanding of vulnerability contributes to grounding the concept of everyday design (practices) philosophically and ethically. This concept has been related to theories of practice and postphenomenology (Wakkary, et al. 2019) but, to our knowledge, it has not been explicitly related to the concept of vulnerability. Viewing everyday design practices through the lens of vulnerability helps to better understand that participating in everyday practices contributes to a world that is always breaking (Jackson, 2014) and that is always in the making (Akama \& Prendiville, 2013). In contrast to critics of the dominance of modernist thinking in design (cf. to break is to fail), these design researchers (also e.g., Garud et al., 2008; Storni, 2014) share with philosophers and anthropologists (e.g., Das, 2015; Donatelli, 2016; Laugier, 2016) who situate vulnerability in and as everyday and often unnoticed encounters, the (world-)view that vulnerability exists everywhere and is not limited to or characteristic of late modern or neoliberal societies.

Through the lens of vulnerability, (everyday) design practices can be understood as care practices; for it are 'activities by which we act to organize our world so that we can live in it as well as possible' (Laugier, 2015, p. 213). However, without offering guarantee of a smooth harmonious world (Puig de la Bellacasa, 2012) as design 'always possesses within itself the simultaneous potentiality for both good and evil' (Buwert, 2017, p. 1). In designing, professional and everyday designers alike can only try to share what they find valuable to pass on but they never have control over it; it cannot be decided beforehand, or be presumed to take place, or be expected to last (cf. Hodgson \& Ramaekers, 2019). Alternative routes are always possible, even, as we have seen, in a highly organised and controlled environment like a paediatric oncology ward. The understanding of everyday design through the lens of vulnerability demands a shift in thinking about what design is and what it does (cf. Moe \& Friedman, 2020). For professional designers this lens may be helpful to raise awareness of their role as participants in care(-networks) and offer insights into how design through use can be supported and facilitated. The lens of vulnerability questions the idea that designed spaces and artefacts by themselves are healing, therapeutic, caring or not, as design and care always need to be considered interdependently. Instead, in recognizing the vulnerability of forms of life, this lens invites approaches to design which support and provoke unspectacular moments of care that holds people's lives and our world together in the continuous flow of events. 
3.2 The contribution of design research to vulnerability

Our article makes clear that in making an enabling understanding of vulnerability more explicit in design research focussing on everyday and ongoing design, design research can contribute to scholarship on vulnerability in anthropology and philosophy. Understanding designed things as open and leaky directs attention away from situating vulnerability almost exclusively in (relations between) human beings (cf. Cipolla, 2018). Design researchers who focus on mundane practices and understand repair, support, revaluing, and maintenance as everyday design can provide a theoretical lens and methodological tools to pay closer attention (to become more sensitive) to and make noticeable the spatial and material surroundings of our social lives - as an active part of our being in various ways (cf. Stender, 2017). Designers and researchers who, through different modes of inquiry, take the vulnerability of the ordinary as a starting point are able to question arrangements of carelessness towards those humans and other-than-humans rendered less visible in our society. Design research is in a good position to recognize, and to give voice and attention to those (f)actors which are generally undervalued or are broken down precisely because they play a part in unnoticed, invisible tasks and take care of other people and things. As such, design research may contribute to vulnerability scholars' work to undo the world such as it is (Ferrarese, 2016). Exploring everyday design practices thus may become a way to study vulnerability in and as everyday and often unnoticed encounters.

\section{Acknowledgements}

This article is dedicated to the memory of Zoran. We thank the three participating children for sharing their time and insights, the hospital staff for their support, the advisory board of the research project for their suggestions, and Stefan Ramaekers for his attentive encouragement. Early versions of the case study were presented at the 'Association of Social Anthropologists of the UK and Commonwealth Conference' (University of East Anglia, 2019), the 'Ethnography in co-operation summer school' (KU Leuven \& University of Siegen, 2019), and the 'International perspectives on stages of life winter school' (University of Bielefeld, 2020). We thank the participants in these events for their questions and comments, which helped to structure our thoughts in this article. We thank both reviewers and the guest editor for their always constructive remarks and feedback throughout the review process. Many thanks also to our Research[x]Design colleagues for the discussions during e-coffee and -lunch breaks, which made working from home somewhat easier during a lockdown. 


\section{Literature}

Adams, A. (2017). Decoding modern hospitals. Architectural Design 87(2), 16-23.

Adams, A., Theodore, D., \& McKeever, P. (2009). Pictures of health. In L. Lerner (Ed.), Depicting Canada's children (pp. 259-278). Wilfrid Laurier University Press.

Akama, Y. (2015) Being Awake to Ma. Co:Design, 11(3-4), 262-74.

Akama, Y., \& Prendiville, A. (2013). Embodying, enacting and entangling design. Swedish Design Research Journal, 1(1), 29-41.

Akama, Y., Pink, S., \& Fergusson, A. (2015, April). Design+ Ethnography+ Futures. In Proceedings of the 33rd Annual ACM Conference Extended Abstracts on Human Factors in Computing Systems (pp. 531542).

Almohamed, A., \& Vyas, D. (2016, June). Designing for the Marginalized. In Proceedings of the 2016 ACM Conference Companion Publication on Designing Interactive Systems (pp. 165-168).

Araujo, M. T., Velloso, I. S. C., Ceci, C., \& Purkis, M. E. (2020). The significance of overlooked objects. Nursing Inquiry, 27(1), e12306.

Awan, N., Schneider, T., \& Till, J. (2011). Spatial agency. Routledge.

Bache, I., Reardon, L., \& Anand, P. (2015) Wellbeing as a wicked problem. Journal of Happiness Studies, 17(3), 893-912.

Bates, V., (2018). 'Humanizing' healthcare environments. Des. Health 2(1), 5-19. https://doi.org/10.1080/24735132.2018.1436304.

Bartram, R. (2016). Housing and social and material vulnerabilities. Housing, Theory and Society, 33(4), 469-483.

Boeva, Y., \& Foster, E. (2016). Making. IxD\&A, 30, 65-74.

Boys, J. (2016). Architecture, place and the 'Care-Full' design of everyday life. In: C. Bates, R. Imrie, K. Kullman (Eds.), Care and design (pp. 155-177). John Wiley \& Sons.

Brown, K. (2011) Vulnerability. Journal of Ethics and Social Welfare, 5(3), 313-321.

Brown, K., Ecclestone, K., \& Emmel, N. (2017). The many faces of vulnerability. Social Policy and Society, 16(3), 497-510.

Brownlie, J., \& Spandler, H. (2018). Materialities of mundane care and the art of holding one's own. Sociology of health \& illness, 40(2), 256-269.

Butler, J., Gambetti, Z., \& Sabsay, L. (Eds.). (2016). Vulnerability in resistance. Duke University Press.

Burrell, K. (2014) Spilling over from the street. Home Cultures, 11(2), 145-166.

Buwert, P. (2017). Potentiality: the ethical foundation of design. The Design Journal, 20(sup1), S4459S4467. 
Cipolla, C. (2018). Designing for Vulnerability. She Ji: The Journal of Design, Economics, and Innovation, 4(1), 111-122.

Clements, H., Valentin, S., Jenkins, N., Rankin, J., Baker, J. S., Gee, N., ... \& Sloman, K. (2019). The effects of interacting with fish in aquariums on human health and well-being. PloS one, 14(7), e0220524.

Cracknell, D., White, M. P., Pahl, S., Nichols, W. J., \& Depledge, M. H. (2016). Marine biota and psychological well-being. Environment and Behavior, 48(10), 1242-1269.

Culén, A. L., \& Van Der Velden, M. (2013, August). The digital life of vulnerable users. In Scandinavian Conference on Information Systems (pp. 53-71). Springer.

Das, V. (2007). Life and words. University of California Press.

Das, V. (2015). Affliction. Fordham Univ Press.

Desjardins, A., \& Wakkary, R. (2013, June). Manifestations of everyday design. In Proceedings of the 9th ACM Conference on Creativity \& Cognition (pp. 253-262). ACM.

Donatelli, P. (2016). Vulnerability and life forms. Etica \& Politica, 18(3), 59-74.

Duque, M., \& Popplow, L. (2019). Caring with Others. Nordes, 8.

Ferrarese, E. (2016). Vulnerability. Critical Horizons, 17(2), 149-159.

Garud, R., Jain, S., \& Tuertscher, P. (2008). Incomplete by design and designing for incompleteness. Organization studies, 29(3), 351-371.

Gatehouse, C., Wood, M., Briggs, J., Pickles, J., \& Lawson, S. (2018, April). Troubling Vulnerability. In Proceedings of the $2018 \mathrm{CHI}$ (pp. 1-13).

Giaccardi, E., Speed, C., Cila, N., \& Caldwell, M. (2016). Things as co-ethnographers. In: R.C. Smith, K.T. Vangkilde, M.G. Kjærsgaard, T. Otto, J. Halse, \& T. Binder (Eds.), Design Anthropology Futures (pp. 235248). Bloomsbury.

Gibson, J.J. (1979). The Ecological Approach to Visual Perception. Houghton Mifflin Harcourt.

Gieryn, T. F. (2002). What buildings do. Theory and society, 31(1), 35-74.

Gilson, E. (2011). Vulnerability, ignorance, and oppression. Hypatia, 26(2), 308-332.

Gilson, E. (2013). The ethics of vulnerability. Routledge.

Gilson, E. C. (2016). Vulnerability and victimization. Signs, 42(1), 71-98.

Gilson, E. C. (2018). Beyond Bounded Selves and Places. Journal of the British Society for Phenomenology, 49(3), 229-242.

Graziano, V., \& Trogal, K. (2017). The politics of collective repair, Cultural Studies, 31(5), 634-658.

Gunn, W., Otto, T., Smith, R.C. (2013). Design Anthropology. Bloomsbury Academic. 
Hackett, A., Procter, L., \& Seymour, J. (2015). Introduction. In: J. Seymour, A. Hackett, \& L. Procter (Eds.), Children's Spatialities (pp. 1-17). Palgrave Macmillan.

Haisman Page, T. (2016). Unspectacular Events (Doctoral dissertation, Goldsmiths, University of London).

Han, C. (2013). Suffering and the pictures of anthropological inquiry. HAU: Journal of Ethnographic Inquiry, 3(1), 231-240.

Han, C. (2018). Precarity, precariousness, and vulnerability. Annual Review of Anthropology, 47, 331343.

Hodgson, N., \& Ramaekers, S. (2019). Dogtooth. In: N. Hodgson, \& S. Ramaekers, Philosophical Presentations of Raising Children (pp. 76-83). Palgrave Macmillan.

Imrie, R., \& Thomas, H. (2008). The interrelationships between environment and disability. Local Environment, 13(6), 477-483.

Ingold, T. (2008). Bringing Things to Life. ESRC National Centre for Research Methods, NCRM Working Paper Series, 1-15.

Jacobs, J. M., \& Merriman, P. (2011). Practising architectures. Social \& Cultural Geography, 12(3), 211222.

Jackson, S. J. (2014). Rethinking Repair. In: T. Gillespie, P. Boczkowski, \& K. Foot (Eds.), Media Technologies (pp. 221-240). MIT Press.

Kang, K.-Y., \& Lee, K.-H. (2014). Vulnerability Assessment Model. Journal of Asian Architecture and Building Engineering, 13(2): 413, DOI: jaabe.13.413.

Kendall, A., Keoleian, G. A., \& Lepech, M. D. (2008). Materials design for sustainability through life cycle modeling of engineered cementitious composites. Materials and Structures, 41(6), 1117-1131.

Kim, H. \& Lee, W. (2014). Everyday design as a design resource. International Journal of Design, 8(1).

Kuijer, L., Nicenboim, I., \& Giaccardi, E. (2017, June). Conceptualising resourcefulness as a dispersed practice. In Proceedings of the 2017 Conference on Designing Interactive Systems (pp. 15-27).

Lagomarsino, S. (2006). On the vulnerability assessment of monumental buildings. Bulletin of Earthquake Engineering, 4(4), 445-463.

Langfield, J., \& James, C. (2009). Fishy tales. British Journal of Occupational Therapy, 72(8), 349-356.

Laugier, S. (2015). The Ethics of Care as a Politics of the Ordinary. New Literary History, 46(2), 217-240.

Laugier, S. (2016). Politics of vulnerability and responsibility for ordinary others. Critical Horizons, 17(2), 207-223.

Law, J. (2019). Material semiotics. heterogeneities.net. 
Lindström, K., \& Ståhl, Å. (2019). Caring design experiments in the aftermath. In The 8th Bi-Annual Nordic Design Research Society Conference-Who Cares? (pp. 1-9). Nordic Design Research.

Macdonald, A. S., Teal, G., \& Moynihan, P. J. (2010, November). An inclusive design methodology for redesigning the food service for vulnerable older adult hospital patients. In Proceedings of the 3rd International Conference for Universal Design.

Maestri, L., \& Wakkary, R. (2011, November). Understanding repair as a creative process of everyday design. In Proceedings of the 8th ACM conference on Creativity and cognition (pp. 81-90).

Manning, E. (2016). The minor gesture. Duke University Press.

Miller, D. (1988). Appropriating the State on the Council Estate. Man, 23(2): 353-372.

Milstein, D., (2015). Constructing collaborative interpretations. In P. Smeyers, D. Bridges, N.C. Burbules, \& M. Griffiths, (Eds.), International Handbook of Interpretation in Educational Research (pp. 529-549). Springer.

Moe, K. \& Friedman, D. S. (2020). All Is Lost: Notes on Broken World Design. Places Journal, October 2020. Accessed 04 Nov 2020. <https://placesjournal.org/article/all-is-lost-notes-on-broken-worlddesign/>

Mol, A. (2008). I eat an apple. Subjectivity, 22(1), 28-37.

Mol, A., Moser, I., \& Pols, J. (Eds.). (2015). Care in practice (Vol. 8). transcript Verlag.

Nicolini, D., 2009. Zooming in and out. Organization Studies, 30(12), 1391-1418.

Noens, P. (2017). Family 'matters': Re-'taking' upbringing in a culture of parenting (doctoral dissertation, KU Leuven).

Olalquiaga, C. (1998). The artificial kingdom. Pantheon Books.

Petherbridge, D. (2016). What's Critical about Vulnerability? Hypatia, 31(3), 589-604.

Pink, S. (2013). Doing Visual Ethnography. Sage.

Pink, S., Mackley, K. L., Morosanu, R., Mitchell, V., \& Bhamra, T. (2017). Making homes: ethnography and design. Bloomsbury Publishing.

Pink, S., Salazar, J. F., \& Duque, M. (2019). Everyday mundane repair. Tapuya, 1-20.

Prior, L. (1988). The architecture of the hospital. Br. J. Sociol. 39(1), 86-113.

Puig de la Bellacasa, M. P. (2012). Nothing comes without its world. The Sociological Review, 60(2), 197216.

Raff, J.-H., \& Melles, G.(2015). Design without Designers. Design Philosophy Papers, 10(1), 23-33. 
Ramioul, C., Tutenel, P., \& Heylighen, A. (2020, March). Reflections on Methods for Exploring Children's Encounter with the Urban Environment. In: P. Langdon, J. Lazar, A. Heylighen, \& H. Dong, Designing for Inclusion (pp. 107-114). Springer.

Rautio, P., (2013). Children who carry stones in their pockets. Child Geogr., 11(4), 394-408.

Rokach, A. (2016). Psychological, emotional and physical experiences of hospitalized children. Clinical Case Reports and Reviews, 2(4), 399-401.

Schatzki, T. R. (2002). The site of the social. Penn State Press.

Schepers, S., Dreessen, K., \& Zaman, B. (2018). Rethinking children's roles in Participatory Design. International journal of child-computer interaction, 16, 47-54.

Schmitt, S. B. (2017). Making charismatic ecologies. In: Schroer, S.A., \& Schmitt, S.B. (Eds.), Exploring atmospheres ethnographically (pp. 98-101). Routledge.

Shildrick, M. (2002). Embodying the monster. Sage.

Slegers, K., Wilkinson, A., \& Hendriks, N. (2013, April). Active collaboration in healthcare design. In CHI'13 Extended Abstracts on Human Factors in Computing Systems (pp. 475-480). ACM.

Stam, L., Verbeek, P.P., \& Heylighen, A. (2020). Between specificity and openness. Design studies. Doi: /10.1016/j.destud.2019.11.010.

Stender, M., (2017). Towards an Architectural Anthropology. Architectural Theory Review, 21(1), 27-43.

Storni, C. (2014). The problem of de-sign as conjuring. In Proceedings of the 13th Participatory Design Conference: Research Papers-Volume 1 (pp. 161-170).

Sumartojo, S., Pink, S., Duque, M., \& Vaughan, L. (2020). Atmospheres of care in a psychiatric inpatient unit. Design for Health, 4(1), 24-42.

Tutenel, P., Ramaekers, S., \& Heylighen, A. (2019a). Conversations between procedural and situated ethics. The Design Journal, 22(sup1), 641-654.

Tutenel, P., Ramaekers, S., \& Heylighen, A. (2019b). Understanding children's spatiality in cancer care environments. Health \& place, 60, 102211.

Van der Geest, S., 2015. How can it be!?. Medicine Anthropology Theory, 2.

van Dijk, L., \& Rietveld, E. (2017). Foregrounding sociomaterial practice in our understanding of affordances. Frontiers in Psychology 7.

Vines, J., McNaney, R., Clarke, R., Lindsay, S., McCarthy, J., Howard, S., ... \& Wallace, J. (2013, April). Designing for-and with-vulnerable people. In CHI'13 Extended Abstracts on Human Factors in Computing Systems (pp. 3231-3234).

Virokannas, E., Liuski, S., \& Kuronen, M. (2018). The contested concept of vulnerability. European Journal of Social Work, 1-13.

Wakkary, R. (2009). Anything is a fridge. Interactions, 12-17. 
Wakkary, R., \& Maestri, L. (2008). Aspects of everyday design. Intl. Journal of Human-Computer Interaction, 24(5), 478-491.

Wakkary, R., \& Maestri, L. (2011, May). Four factors of change. In CHI'11 Extended Abstracts on Human Factors in Computing Systems (pp. 1603-1608).

Wakkary, R., Hauser, S., \& Oogjes, D. (2019). Displacement. In Social Practices and Dynamic NonHumans (pp. 151-171). Palgrave Macmillan, Cham. 